\title{
Mapping The Field of Lifelong (Formal and Informal) Learning and (Paid and Unpaid) Work
}

\author{
David $W$. Livingstone and Margrit Eichler, \\ Department of Sociology and Equity Studies, OISE/University of Toronto.
}

Joint Keynote Address, The Future of Lifelong Learning and Work International Conference, June 20, 2005, Toronto

[N.B. Livingstone text appears first, followed by Eichler text focused on "Unpaid Work and Lifelong Learning". The conference presentation will be in different, interspersed order.l

\section{Paid and Unpaid Work}

A generic definition of "work" would include any activity directed toward making or doing something. "Work" is now commonly used as synonymous with "earning a living" through paid employment in the production, distribution and exchange of goods and services commodities. There has been an increasing tendency since rise of market-based economies for work to be identified in popular thought and practice with commodity exchange and paid wage labour. Growing commodification served to obscure unpaid labour. More recently, some aspects of unpaid housework and community volunteer labour have received more recognition for various reasons, including relative scarcity and resistance to their own further commodification ${ }^{\mathrm{i}}$.

Most of us still must do some household work and many need to contribute to community labours in order to reproduce society and ourselves. Both housework and community volunteer work are typically unpaid and underappreciated, but they remain essential for our survival and quality of life (see Waring, 1988) All three forms of labour should be included in any general accounting of contemporary work practices. Margrit Eichler will speak more specifically about dimensions of housework, including emotion work and coordination, in a moment.

\section{Paid Work}

Since the rise of industrial capitalism, the forms, extent and duration of paid employment have been increasingly determined by the profitability of private enterprises, as well as the relative bargaining strength of business owners and hired labourers and the availability of labour-saving technologies. In recent decades, the concentration of large corporations, extensive automation and declining unionization have lead to significant changes in employment conditions, including increasing levels of chronic unemployment, intensification of employment hours, a rise in temporary jobs as well as much dispute about the skill requirements to perform most of the jobs in the "new economy".

The Changing Nature of Work and Lifelong Learning in the New Economy Research Network (WALL), supported by the SSHRC, conducted a large-scale national survey in 
2004 (see www.wallnetwork.ca). Compared to another national survey conducted in 1998, New Approaches to Lifelong Learning (NALL) (see www.nall.ca), there were significant increases in time devoted to paid employment during this period, from an average of 38 to 40 hours per week while the proportion of the active labour force employed for more than 50 hours a week rose from around $15 \%$ to around $20 \%$. The participation rate in paid employment reached about 68 percent of the working age population, the highest rate on record (compare Statistics Canada, 2004). A long-time trend toward part-time jobs may have slowed in this period of economic recovery, but those in part-time jobs appear to be working longer hours as well, without increasing benefits. The official unemployment rate remains stuck at over 7 percent and has fluctuated upward from that rate since the mid-1970s.

In terms of the stability of employment, about a third of the active labour force moved to a new job in the past five years. Many workers have experienced significant organizational changes at their workplaces. Around 40 percent have seen downsizing of employees, growth in multi-skilling/job rotation and growing reliance on part-time or temporary workers, while around a third have witnessed increased overtime. While downsizing was common practice in many enterprises in the mid-1990s, the incidence of job rotation and reliance on part-timers appears to have increased in recent years (Statistics Canada, 1998, p. 17). When asked for their general impressions of skill requirements, about half of all employees think that the level of skill to perform their job has increased in the past five years while very few perceive de-skilling. However, when asked more directly about the level of formal education required for their job, their overall ratings are very similar to a comparable national survey done in 1982, with around 45 percent of hired employees having jobs requiring post-secondary education (see Scholtz and Livingstone, 2005). It seems that there has been a very significant amount of organizational restructuring in recent years with declining stability and longer hours for many jobholders. But in spite of widespread acceptance of the rhetoric of increasing skill demands and a rapidly emerging knowledge-based economy, there is little objective evidence that the actual performance requirements of the changing job structure have increased significantly in recent years (cf. Livingstone, 2004; Handel, 2000). Workers are being called upon to use a wider array of skills for longer hours, but not necessarily a higher level of skill.

\section{Unpaid Work}

Unpaid housework is reported by over 90 percent of Canadian adults who indicate they spent around 17 hours a week doing it in both 1998 and 2004. For homemakers who devote themselves primarily to housework, the average is now around 40 hours per week and appears to have increased over this period. If we express labour expended in terms of the total amount of paid employment time and housework time done by all Canadian adults, the averages are around 25 hours of paid employment and 15 hours of housework per week in these recent surveys. By these general estimates, total employment hours may have increased, but total housework hours have not. While the small numbers of primary homemakers are doing more hours of housework, most others may be doing marginally less. The point of these estimates is simply to establish that unpaid housework 
is a very substantial portion of the work that most of us do and deserves to be consistently recognized on its own merits.

Indeed, these estimates exclude other essential labours of childcare and eldercare. Over a third of Canadian adults report some involvement in unpaid childcare, for an average of over 30 hours per week. About 15 percent are now involved in eldercare, for an average of over 10 hours per week. Add in community work with both voluntary organizations and friends, and even in terms of crude estimates, it is likely that around half of the work that Canadians now do is still unpaid. The crudeness of these estimates must be stressed. Paid employment is typically measured in industrial clock time, another instrument of commodification. While both housework and community volunteer work have been increasingly constrained by paid employment, they do not obey the same rhythms (cf. Sorokin, 1943). Most obviously, childcare responds to the needs of the child. For many mothers this is a constant labour of varying intensity but inherently different than the time measured by a plant or office time clock. Even in terms of clock time measures, mothers with small children are among the longest working people in the country. If they also happen to be employed, clock time fails utterly to grasp the extent of their labours.

The major change in the distribution of work in recent generations has been the massive increase in the participation of married women with children in the paid labour force. This change has put growing pressure on households to reorganize domestic labour to ensure it gets done. The growing reliance on machinery in paid jobs has put an increasing premium on workers' active use of their minds in tending machines and made it more difficult for many workers to turn off their job minds when not officially on the job clock (see Rikowski, 2004). Longer and less defined paid work hours and the consequent time squeeze on unpaid work mean work intensification in both spheres.

While debate over skill requirements of paid work persists, the skill complexity of housework and care work has not even been hinted at by most prior research, as Margrit's studies show.

\section{[Margrit's account of housework presented here.]}

\section{Learning}

A generic definition of learning involves the gaining of knowledge or skill anytime and anywhere through individual and group processes. Learning occurs throughout our lives. The sites of learning make up a continuum ranging from spontaneous responses to everyday life to highly organized participation in formal education programs. The dominant tendency in contemporary thought has been to equate learning with the provision of learning opportunities in settings organized by institutional authorities and led by teachers approved by these authorities. Formal schooling has frequently been identified with continuous enrolment in age-graded, bureaucratically-structured institutions of formal schooling from early childhood to tertiary levels (see Illich, 1971), ignoring other types of instruction in bodies of traditional knowledge in subordinate groups. In addition, further or continuing adult education includes a diverse array of 
further education courses and workshops in many institutionally organized settings, from schools to workplaces and community centres. Such continuing education is the most evident site of lifelong learning for adults past the initial cycle of schooling.

But we also continually engage, as we always have, in intrinsic informal learning activities to acquire knowledge or skill outside of the curricula of institutions providing educational programs, courses or workshops. Informal education or training occurs when mentors take responsibility for instructing others without sustained reference to a preestablished curriculum in more incidental or spontaneous situations, such as guiding them in learning job skills or in community development activities. Finally, all other forms of explicit or tacit learning in which we engage either individually or collectively without direct reliance on a teacher/mentor or an externally-organized curriculum can be termed non-taught self-directed or collective informal learning. As my colleague Allen Tough (1978) has observed, informal learning is the submerged part of the iceberg of adult learning activities. It is likely that, for most adults, informal learning (including both informal training and non-taught learning activities) continues to represent our most important learning for coping with our changing environment. No account of "lifelong learning" can be complete without considering peoples' informal learning activities as well as their initial formal schooling and further adult education courses through the life course.

\section{Formal Education}

Canada has long had one of the highest formal educational attainment levels in the world. But recent post-secondary growth rates remain impressive. The proportion of the age 25to-29 cohort that had completed a university degree was about 4 percent in 1961. The completion rate had quadrupled by 1990 to 17 percent and continued to grow rapidly up to 1998 , when 26 percent of this age group had received degrees. Growth of community college completion has been even greater. Most comprehensive community colleges were created after 1960. By the 1990s, comparable proportions of young people had completed college diplomas as university degrees. While the US and Norway have higher proportions of their adult populations with university degrees, Canada now leads the world in the proportion with either university or college completion. Over 40 percent of Canadian adults 25 to 64 had college or university qualifications in 2000. Other tradevocational programs including registered apprenticeships have been chronically underdeveloped in Canada, but in the early 1990s over 10 percent of those 25 to 64 had some such qualifications; this proportion has since declined. University and college qualifications levels have continued to grow and now the majority of adult Canadians have some form of post-secondary certification (see Statistics Canada, 2003, p.135-144), compared to a very small minority just two generations ago.

But before applauding Canada as world leader in higher education, note two major limitations. First, Canada continues to trail most OECD countries in the provision of early childhood education. Less than half of all 3-to-5 year-olds attend pre-elementary programs, and only marginal increases have taken place over the past decade (Statistics Canada, 2000, p. 37). In light of the massive amount of research documenting the 
multiple benefits of early participation (e.g., McCain and Mustard, 1999), significant future increases in junior kindergarten programs may be anticipated.

Secondly, previous general increases in post-secondary enrolment mask persistent and now increasing inequities of access by economic background. Youths from poorer economic origins have always been under-represented in post-secondary institutions. Tuition fees and average student debt loads have more than doubled during the past decade (Statistics Canada, 2000, p. 67) while average family income has remained the same in real dollar terms. Recent studies indicate that those from low socio-economic status backgrounds were significantly less likely to attend university in the late 1990s than their counterparts of a decade earlier (Livingstone and Stowe, 2001). Aggregate increases in formal educational attainment are not now reducing relative educational inequalities by economic origin.

Further or continuing adult education participation in courses and workshops can include, for example, courses in job retraining or upgrading, second language training, courses to complete a diploma or degree program, and a wide array of general interest courses of different durations ranging from accounting processes to zoo-keeping. In light of the growth of post-secondary education, recent surveys have found it increasingly difficult to distinguish adult course participation from completion of the initial cycle of schooling ${ }^{\text {ii }}$. The simplest solution is to count all forms of adult (i.e. over 18) participation in organized educational programs, and note those who are also registered as students in school certification programs.

National surveys have found that participation in adult education underwent very rapid growth from 1960 to the early 1990s. In 1960, the first known government survey (Dominion Bureau of Statistics, 1963) found about 4 percent of all Canadians over 17 years of age were estimated to be enrolled in any sort of educational institution course. By the early 1980s (Devereaux, 1985), about 20 percent were enrolled annually. By the early 1990s, the rate exceeded 30 percent (Statistics Canada, 1997a). During the 1990s, adult education participation appeared to decline somewhat according to official government statistics (Statistics Canada, 2001). Various reasons have been suggested for this apparent decline, but it may well be largely an artefact of excluding those young adults who prolonged or returned to their schooling in the face of poor job markets. In any case, our recent surveys have found that participation in formal training courses has grown to over 43 percent in 1998 and nearly 45 percent in 2004. If all of those over 18 registered in school programs are excluded, this still amounts to around 35 percent of all adults participating in some form of course annually. Canadian adult education participation has grown very rapidly over the past two generations. But it remains significantly lower than that of various other areas, notably Scandinavia (Statistics Canada, 1997a).

\section{Informal Learning}

Informal learning activities are much more difficult to estimate than adult educational participation. Informal learning includes virtually any non-institutionalized learning in 
which adults choose to engage. Intentional informal learning is distinguished from more tacit informal learning, as well as from everyday perceptions and general socialization, by peoples' own conscious identification of the activity as significant learning (see Eraut, 1999). To study informal learning empirically, most researchers have focused on those things that people can identify for themselves as actual learning projects or deliberate learning activities beyond educational institutions. There are numerous obstacles to studying informal learning but there is a growing consensus that any discussion of lifelong learning of adults beyond their initial cycle of schooling requires at least some address to informal learning.

The NALL and WALL national surveys of learning and work in 1998 and 2004 had a primary focus on informal learning (for further information on these research networks and the full interview schedules, see the NALL website: $w$ ww.nall.ca and the linked WALL website: www.wallnetwork.ca). These surveys addresses all four basic forms of learning, but with a special focus on intentional informal learning, as well as all three forms of work and a variety of social background factors. The survey respondents were first given a definition of informal learning as including anything people do to gain knowledge, skill or. They were then asked to indicate their participation in four kinds of informal learning: employment-related; community volunteer work-related; household work-related; and other general interest-related. In each case, a list of possible learning topics was read. The basic findings follow, with reference to prior studies where relevant for comparative purposes ${ }^{\mathrm{iii}}$ and with special attention to a further in-depth study of housework-related informal learning. These estimate exclude those registered as students in degree or diploma programs at any level of formal schooling.

Table 1 Work and General Interest Related Informal Learning (Average Hours per Week), Canadian Adults, 1998-2004*

$\begin{array}{cccccc} & \text { Job } & \text { Housework } & \begin{array}{c}\text { Volunteer } \\ \text { work }\end{array} & \begin{array}{c}\text { General } \\ \text { interest }\end{array} & \text { Total } \\ 1998 & 6.6 & \underline{6.2} & 4.3 & 6.0 & 16.0 \\ 2004 & 4.6 & 5.0 & 3.1 & 4.3 & 11.9\end{array}$

*Excludes students registered in degree/diploma programs Sources: NALL Survey, 1998 (N=1562); WALL Survey, 2004 (N=9063).

Paid Work-related Informal Learning 
Of the 68 percent of the adult population who were employed for at least an hour a week at some point during the prior year, 82 percent reported that they were involved in some form of job-related informal learning in 2004. The average number of hours devoted to such job-based learning was over 6 hours per week in 1998, dropping to under 5 hours in 2004. Around 15 percent were estimated to spend less than an hour per week in employment-related informal learning activities, including those who found it too difficult to provide a specific estimate. Less than 10 percent estimated that they spent more than 20 hours per week, suggesting that even when respondents are given extensive opportunities to identify job-related informal learning, they try to distinguish explicit informal learning from other activities, recognize both the time constraints of multiple other activities in the 168-hour week, and are very unlikely to regard learning as a "seamless web" occupying most of their paid work time.

\section{Household Work-related Informal Learning}

Those involved in at least one hour of household work over the prior (around 90\%) averaged about 6 hours per week in informal learning related to their household work in 1998, dropping to 5 hours in 2004. Again, there are small numbers at the extremes, with around 10 percent indicating they devote less than an hour per week to housework-related informal learning and about 5 percent saying they spend more than 20 hours per week in such learning. Given the greater proportion of Canadians involved in housework than in paid employment, and the similar average hours devoted to informal learning related to employment, it appears that we now devote about as much aggregate time to informal learning related to housework as to paid employment.

\section{[Margrit's account of housework-based informal learning here.]}

\section{Community Volunteer Work-related Informal Learning}

Those involved in organized community work over prior year (over $40 \%$ in 1998 , declining to about one-third in 2004) devoted an average of about 4 hours a week to community-related informal learning. The majority of those who participate in community work indicate that they devote one hour or less per week to related informal learning activities, while less than 5 percent devote more than 10 hours per week. The relatively low levels of participation in community volunteer work and related informal learning are consistent with the fact that this is the most discretionary type of work in advanced industrial societies, and many people simply choose to opt out.

\section{Other General Interest Informal Learning}

Most people engage in some other types of informal learning related to their general interests and not directly connected to any of the three forms of work. Those who do so (around 80\%) spent on average almost 6 hours a week on these learning activities in 1998 , declining to just over 4 hours in 2004. Around 40 percent of respondents spend an 
hour or less per week in informal learning related to all of these general interests. The majority spend no more than two hours, while less than 10 percent devote more than 10 hours a week to such general interest learning. While there is evidently very wide participation in informal learning related to diverse interests, the incidence of workrelated informal learning appears to be considerably greater - if learning related to both paid and unpaid work is included.

\section{Total Involvement in Informal Learning}

Most Canadian adults (around 85\%) are involved in some form of informal learning activities that they identify as significant. These surveys provides estimates of the amount of time that all Canadians, including those who say they do no informal learning at all, are spending in all four areas (employment, community, household, and general interest). The average number of hours devoted to informal learning activities by all Canadian adults during 1998 was over 15 hours per week. In 2004, the average had dropped to about 12 hours per week. These average estimates emanate from surveys devoted primarily to identifying the existence of intentional informal learning on multiple topics in several spheres of life activities. Virtually all prior empirical studies of informal learning found considerable initial reluctance among respondents to identify their learning outside educational institutions as legitimate learning ${ }^{\mathrm{iv}}$. It is only when people had an opportunity to reflect on actual learning practices in the context of their daily lives that much intentional informal learning was recognized as such by the learners themselves. Intentional informal learning activities often also occur in combination with other social activities. While this makes time estimates more difficult and less exact, it is no grounds to either devalue or ignore informal learning processes.

Most other international surveys that have attempted to estimate the incidence of informal learning have found similar magnitudes of these learning activities (see Livingstone, 2005 for a summary). Generally, the average estimated time devoted to informal learning has been found to significantly exceed the time devoted to formal educational activities. About three-quarters of Canadian adults now say they are spending 6 hours or more each week in some kind of intentional informal learning activities, most of it related to paid or unpaid work.

When we asked which of these learning activities are most important in the respective spheres of activity, the most common responses were about computer skills related to employment, home renovations and household cooking skills, communications skills through community volunteer work, and general interest learning about health issues. Clearly, the overwhelming majority of Canadian adults now regularly spend substantial amounts of time in these pursuits, and they recognize this intentional informal learning as a significant aspect of their daily lives.

\section{Relations Between Schooling, Adult Education and Informal Learning}

Schooling and adult education continue to be mutually reinforcing: the more schooling people have obtained, the more likely they are to participate in continuing education 
courses, as Table 2 shows. The majority of those who have completed university programs took some form of adult education during the past year, about 40 percent of those with college diplomas, a third of high school graduates and less than 20 percent of school dropouts. A very similar pattern occurs for plans to take more education courses in the future. These basic relationships have been widely documented (e.g. Cross, 1981; Devereaux, 1985; Tuijnman, 1989; Courtney, 1992). While both school attainments and adult education made very impressive aggregate gains in recent generations, participation in adult education courses still tends to reproduce prior differences in educational attainments. The apparent decline in adult course participation rates between 1998 and 2004 for all but school dropouts is at least partly because it excludes the growing numbers of adults currently registered as students in degree/diploma programs

As Table 2 also shows, informal learning is not strongly associated with either level of schooling or continuing adult education. School dropouts are only slightly less likely to participate in informal learning activities than those with higher levels of formal education and those who do spend as much time as on them as university graduates. Lack of motivation to learn per se is not a major factor in their non-participation in adult education courses. Our longitudinal analysis finds that among all Canadians who did not take courses in either 1998 or 2004 there was declining involvement in job-related informal learning (Livingstone and Stowe, 2005). But most adults are generally active learners engaged in a considerable array of different learning activities. In spite of the expansion of schooling and adult courses, most of this activity takes place outside the walls of educational institutions

Table 2. Participation in Adult education and Informal Learning by Formal Educational Attainment, All Adults, 1998/2004*

$\begin{array}{lcccc}\text { SCHOOLING } & \begin{array}{c}\text { Taken adult } \\ \text { education course } \\ \text { or workshop past } \\ \text { year }\end{array} & \begin{array}{c}\text { Plan to take } \\ \text { course }\end{array} & \begin{array}{c}\text { Informal } \\ \text { learning }\end{array} & \begin{array}{c}\text { Informal } \\ \text { learning }\end{array} \\ & (\%) & & & \\ \text { No diploma } & 98 / 04 & (\%) & (\%) & \text { (Hrs/week) } \\ \text { High school diploma } & 15 / 18 & 24 / 17 & 78 / 64 & 18 / 15 \\ \text { Community college } & 40 / 33 & 49 / 35 & 95 / 83 & 17 / 15 \\ \text { University degree } & 55 / 42 & 59 / 44 & 95 / 88 & 15 / 13 \\ \text { TOTAL (\%) } & 64 / 53 & 64 / 50 & 99 / 98 & 14 / 12 \\ & 37 / 34 & 43 / 34 & 89 / 81 & 16 / 13 \\ \text { *Excludes students registered in degree/diploma programs } & & \end{array}$

Any study of lifelong learning should attend to differences in learning through the life course. These surveys have found that young adults are most likely to take further education courses and more likely than older people to value formal courses rather than their own independent informal learning efforts. But younger adults tend to do the most informal learning as well. The findings also confirm the longstanding relationship of 
declining participation in adult education with aging. The increasing educational attainment of Canadians has led to increased course participation at all ages. But declining course participation in the later years remains pronounced. Those over 65 indicate that they still spend just a little less than the national average of about 12 hours per week in various informal learning activities. Aging is not significantly associated with a declining incidence of informal learning beyond the intense period of entry into adulthood. The stereotype that the active interests of older adults rapidly diminish as they approach and enter their retirement years is contradicted by both these survey findings and other recent research (see Glendenning and Stuart-Hamilton, 1995). The older we get, the more likely we are to rely on our prior learning experiences rather than formal courses to guide our further learning. The notion that older people do not continue to be active learners should be discarded.

In sum, Canadians are now spending large and unprecedented amounts of time in school attendance, adult education courses, and informal learning activities. Canadians' postsecondary educational attainments, after two generations of extraordinary growth, now lead the world. Participation in adult education appears to have grown equally quickly during this period. Around half of Canadian adults plan to take further education courses in the near future. Although there are few available measures of informal learning, the incidence of adults' intentional informal learning activities related to paid work, housework, volunteer work and general interests appears to be far more extensive than participation in formal education. The vast majority of Canadian adults are continually involved in a wide array of activities in pursuit of more knowledge, skills and understanding. Most of these learning activities occur informally beyond the recognition of institutional authorities.

\section{Work and Learning}

Learning, the acquisition of skills and knowledge, is the quintessential human activity to cope with our changing environment, and work is what we do with this knowledge. In these generic terms, learning and work are constantly interactive and often simultaneous activities. In this sense, the notion of a "knowledge-based economy" is redundant; all human activities are essentially knowledge-based.

In the much narrower terms of current forms of paid employment, there are many who argue for the necessity of increasing education and training initiatives to respond to the demands of production systems increasingly dependent on information and communications technology and competing in increasingly globalized markets. Nobody is against more knowledge, which is always potentially useful and fulfilling. But we have just documented the exceptional gains Canadians have made in formal schooling and adult course participation in recent years, as well as their more extensive engagement in informal learning. As noted previously, the level of formal education required for jobs has changed only marginally over the past generation and there is little objective evidence that the actual performance requirements of the changing job structure have increased significantly in recent years-- a wider array of skills for longer hours but not a higher level. The consequence has been increasing levels of underemployment, workers 
who have skills and knowledge that they are unable to apply in the jobs available to them (cf Livingstone, 2004; Handel, 2000).

Conversely, the almost universal involvement in housework and its relatively low exchange value has generated very little interest in housework-related learning. This is presumed to be mundane work that anybody can do with little learning. There has been virtually no prior research done on learning associated with housework. But as the Eichler team study is beginning to show, this work not only is more complex than normally thought but often involves quite challenging learning activities which may have much broader relevance than to housework alone.

\section{Concluding Remarks}

The purportedly low literacy level of many Canadian adults, as measured on recent international standardized tests (e.g. Statistics Canada, 1996, 2005) has been of great concern to literacy advocates, policy makers and some employers. The increasing marginalization of school dropouts with functional literacy problems and declining capacity to do paid work is a serious problem and needs immediate attention. So does Canada's chronic failure to develop a domestic apprenticeship system to produce enough skilled trades people. But the literacy panic has been overblown. The vast majority of Canadian workers are adequately qualified for their jobs and increasing numbers are overqualified in terms of their formal education and literacy levels in relation to job demands, not underqualified (cf. Krahn and Lowe, 1998). The recognition of the huge amount of informal learning these workers are doing, most notably through on-the-job training by mentors and their own self-directed pursuit of new skills, suggests that even most of those who lack formal qualifications are finding ways to continue to perform their jobs quite adequately in relation changing employment conditions.

Housework, on the other hand, is supposed to be so simple that anyone can do it. In fact, to do it well requires learning some very complex activities that many of us may be underqualified to perform because of poor or limited training. Housework should be validated in its own right as well as appreciated as an essential source of lifelong learning for everyday life, citizenship, health and some of the subtlest forms of understanding needed for sustainability in advanced technological society.

Formal education is now a basic human right. It should be supported generally and unconditionally, subject only to people's actual learning capacities and availability of public resources. Educational programs should be constantly revised to transmit the most accurate accumulated wisdom of human inquiry. Our fundamental problems are not with education per se but with its access and use.

Inequitable access to formal education and consequently to rewarding jobs and lives persists. The lack of access to advanced education in this country with the highest global level of overall post-secondary attainment remains a serious deficiency in terms of the youths of working class origins, visible minorities and aboriginals, those with disabilities, as well as women and older people from particular programs. All of these forms of under- 
representation signify large waste of talent.

Secondly, there is serious underemployment of many and growing numbers in the current job structure, especially service and industrial wage workers, as we have documented in detail elsewhere (Livingstone, 2004). The central educational question is not whether we live in a learning society but whether educational institutions and paid workplaces can respond effectively to continuing increases in demand for knowledge and interest in using it.

If we were to redress some of the inequitable educational access problems and if we were to begin to fathom the extent of many people's unused formal and informal knowledge, the imperative to change the current job structure would become more evident. Possible changes include wider stakeholder ownership of enterprises, workplace democracy in terms of decision-making and job design, and redistribution of paid and unpaid work. Such changes could challenge the currently dominant patriarchal form of shareholder, "free market" capitalism. This may explain why, in spite of pervasive rhetoric about "lifelong learning in the new economy", there has been very little grounded research on less formal aspects of learning or on most aspects of unpaid work, to say nothing of the imbalances between our different forms and levels of knowledge and our capacities to use them in our paid and unpaid work. In any case, economic reforms should now be understood as at least somewhat more pertinent than educational ones.

\section{References}

Barton, P.E. (2000). What Jobs Require: Literacy, Education and Training, 1940-2006. Princeton, NJ: Educational Testing Service.

Courtney, S. (1992). Why Adults Learn: Towards a Theory of Participation in Adult Education. London: Routledge.

Cross, K.P. (1981). Adults as Learners: Increasing Participation and Facilitating Learning. San Francisco: Jossey-Bass.

Devereaux, M. (1985). One in Every Five: A Survey of Adult Education in Canada.Ottawa, Statistics Canada and Education Support Section, Secretary of State.

Dominion Bureau of Statistics. (1963). Participants in Further Education in Canada. Ottawa: DBS.

Eraut, M. (1999). "Non-formal Learning in the Workplace - The Hidden Dimension of Lifelong Learning: A Framework for Analysis and the Problems It Poses for the Researcher." Plenary paper presented at the First international Conference on Researching Work and Learning, Leeds University, September 10-12.

Glendenning, F. and I. Stuart-Hamilton (eds.) (1995). Learning and Cognition in Later 
Life. Aldershot: Arena.

Handel, M. (2000). Trends in Direct Measures of Job Skill Requirements. Working Paper No. 301, Jerome Levy Economics Institute. Available on-line: www.levy.org/does/wrkpap/papers.

Illich, I. (1971). Deschooling Society. New York: Harper and Row.

Krahn, H. and G. Lowe. (1998). Literacy Utilization in Canadian Workplaces. Ottawa: Statistics Canada.

Livingstone, D. W. (2002). Working and learning in the information age: A profile of Canadians (No. W/16). Toronto: Canadian Policy Research Network.

Livingstone, D. W. (2004). The Education-Jobs Gap: Underemployment or Economic Democracy. Toronto: Garamond Press (second paperback edition).

Livingstone, D.W. and S. Stowe. (2001). "Class and University Education: Intergenerational Patterns in Canada". NALL Working Paper No. 45. (available from www.nall.ca).

Livingstone, D.W. and S. Stowe. (2005). "A Longitudinal Analysis of Formal and Informal Learning Activities of the Employed Labour Force: Canada 1998-2004". Paper presented at the $3^{\text {rd }}$ annual WALL conference, June 19.

McCain, M.N. and J.F. Mustard. (1999). Reversing the Real Brain Drain: Early Years Study. Final Report. Toronto: Ontario Children's Secretariat.

NALL. (1999). Lifelong Learning Profiles: Findings of the First Canadian Survey of Informal Learning Practices. Website of the Research Network on New Approaches to Lifelong Learning: www.nall.ca.

Putnam, R. (2000). Bowling Alone: The Collapse and Revival of American Community. New York: Simon \& Schuster.

Rikowski, R. (2004). On the impossibility of determining the length of the working-day for intellectual labour. Information for Social Change, 19, 52-60.

Scholtz and D.W. Livingstone (2005). "Knowledge Workers and the "New Economy" in Canada: 1983-2004". Paper presented at the $3^{\text {rd }}$ annual WALL conference, June 19.

Sorokin, Pitirim. 1943. Sociocultural Causality, Space, Time. Durham: Duke University Press.

Statistics Canada. (1996). Reading the Future: A Portrait of Literacy in Canada. 
Ottawa: National Literacy Secretariat, Human resources Development Canada and Statistics Canada.

Statistics Canada. (1997a). Adult Education and Training in Canada: Report of the 1994 Adult Education and Training Survey. Hull: Statistics Canada. (AETS 1993).

Statistics Canada. (1998). The Evolving Workplace: Findings from the Pilot Workplace and Employee Survey. Ottawa: Statistics Canada.

Statistics Canada. (1999a). Adult Education and Training Survey 1998. Ottawa:

Statistics Canada. Catalogue No. 81C0045. (AETS 1997).

Statistics Canada (1999b). Overview of the Time Use of Canadians in 1998. Ottawa: Statistics Canada.

Statistics Canada (2000). Education Indicators in Canada: Report of the Pan-Canadian Education Indicators Program 1999. Ottawa: Statistics Canada.

Statistics Canada. (2001). A Report on Adult Education and Training in Canada Learning a Living. Ottawa: Statistics Canada. Catalogue No. 81-586-XPE (AETS 1998).

Statistics Canada (2003). Education Indicators in Canada: Report of the Pan-Canadian Education Indicators Program 2003. Ottawa: Statistics Canada. Catalogue No. 81-582-XPE.

Statistics Canada (2004). The Canadian Labour Market at a Glance. Ottawa: Statistics Canada. Catalogue No. 71-222-XWE.

Statistics Canada (2005). Learning a Living: First Results of the Adult Literacy and Life Skills Survey. Ottawa: Statistics Canada. Catalogue No. 89-603-XWE.

Tough, A. (1978). "Major learning efforts: Recent research and future directions," Adult education 28: 250 - 63.

Tuijnman, A. C. (1989). Recurrent Education, Earnings, and Well-being: A Fifty-Year Longitudinal Study of a Cohort of Swedish Men. Stockholm: Acta Universitatis Stockholmiensis.

Waring, M. (1988). If Women Counted: A New Feminist Economics. San Francisco: Harper and Row.

\section{Endnotes}

${ }^{\mathrm{i}}$ Housework, including cooking, cleaning, childcare and other often-complex household tasks, has been largely relegated to women and only gained some public recognition as women have gained power through increased participation in paid employment. As community life has become more fragmented with dual- 
earner commuter households, time devoted to community work to sustain and build social life through local associations and helping neighbours has declined, and the productive importance of this work has been rediscovered as "social capital" (Putnam, 2000).

${ }^{i i}$ Surveys of adult education in Canada usually have excluded many adults over 16 who are still involved in their initial cycle of schooling. They have included: adults taking non-credit courses for specific purposes at various locations including schools, paid workplaces and through electronic media; adults who have returned to school part-time to complete certification or upgrade through programs of study; adults who have returned to school full-time if they are supported by their employer; and initial cycle students taking supplementary courses (see Devereaux, 1985; Statistics Canada, 1997a, p. 10). These inclusions and exclusions appear increasingly arbitrary as the initial cycle of formal schooling has extended further into adulthood and young adults have increasingly combined school completion with employment. The transitions between schooling and employment are now both more frequent and more complex. Many people combine both statuses and it is often unclear which one might be primary at any given time. For example, over 10 percent of the adult Canadian population were enrolled in certification-based formal education programs during the 1997-98 period, and around half of these adults were enrolled in these programs while also engaged in paid employment (see Livingstone, 2002).

iii Both the estimates of magnitude and the group differences in intentional informal learning patterns should be treated as preliminary findings. This is because: (1) there are no valid precedents for the specific array and format of items about informal learning used in the NALL and WALL surveys; (2) the prior empirical studies of self-directed learning found no significant group differences; (3) margins of error are nearly as large as the differences noted, especially in the relatively small NALL sample ( $\mathrm{N}=1562)$; and (4) informal learning is a particularly diffuse phenomenon which is prone to wide subjective differences in personal estimates. Further replication studies are much needed to test the reliability of all of these original estimates as well as to determine trends in the incidence of informal learning.

${ }^{\text {iv }}$ Recent attention to the significance of lifelong learning has stimulated government agencies to begin to estimate the extent of informal learning. The 1998 General Social Survey (Statistics Canada, 1999b) contained a few questions on informal learning. About 30 percent of respondents gave an initial positive response, then estimated that they were spending about 19 hours per month on these learning activities, or nearly 5 hours per week. Averaged over the entire sample, this would reduce to about 1.5 hours per week, or about one-tenth of the NALL and WALL estimates. This is very likely a serious underestimate of the actual current extent of intentional informal learning. The initial screening question is posed immediately after a series of questions about initial schooling, adult credit courses and non-credit courses which serve to emphasize the relation between organized education and learning, and provides no opportunity to consider informal learning in relation to any specific learning context. In addition, the question dichotomizes courses and learning on your own, suggesting that you can only do one or the other, which is clearly false. While further survey and case study research is required to provide reliable extent and trend estimates, it is likely that this initial GSS survey effort has merely found the iceberg of intentional informal learning rather than plumbing its depth.

\section{Eichler text follows:}




\title{
UNPAID HOUSEWORK AND LIFELONG LEARNING
}

\author{
by \\ Margrit Eichler \\ Department of Sociology and Equity Studies in Education \\ Ontario Institute for Studies in Education at the University of Toronto
}

\section{Introduction}

There is a fundamental difference between looking at lifelong earning and paid work and lifelong learning and unpaid work: in the first instance, there is a large literature on the subject, in the second, there is almost none. In spite of the notion that informal learning deals with the daily life of people and with making sense of their lives (Garrick 1996; Collins 1998; Williamson 1998), unpaid housework has been virtually ignored in this context (Eichler 2005).

There is also another problem: while we generally understand what we mean with paid work, and while we can expect people to understand what their job is when we ask about learning within the context, this is not so with regard to unpaid housework. For a long time, unpaid housework was not regarded as work at all. While this has changed to some degree, even today we need to establish what constitutes unpaid housework (Eichler and Albanese 2004). We face the problem that many of the aspects of housework are performed without people being conscious and aware of the fact that they are performing this work (Eichler and Matthews 2004). And only when we have answered questions 1 and 2 can we even begin to address the third question: what does the learning look like? It is not possible to reflect on how we learn from what we do not know we are doing.

I will report here on one of the WALL subprojects. To understand the context I will briefly describe the overall project.

\section{Description of Study}

The project was informed, from the beginning, by a critical perspective towards the current sociological approach to housework and hence our understanding of what housework actually is. This starting point explains the structure of the overall project, and provides the context for my remarks of today.

The data collection consists of 4 phases. The 1 . phase consisted of a questionnaire sent to members of various women's groups (and to their partners, in one of the groups) in which we ask them what housework and care work they do and what they learn from it. We received 303 questionnaires back. The intent of this phase was not to find out what they do, but what they say they do. We wanted to know whether the women (and the men) 
would come up with the same restrictive list that is employed by sociologists. The answer: most did have a list similar to that used by sociologists, some, however, listed many more activities. Most people listed cleaning, laundry, meal preparation, gardening, shopping doing the dishes, childcare if they had children at home - the familiar items on such lists. A few listed emotion work, maintaining social relations, administrative functions and other superordinate activities. This means that the majority of respondents were not aware of the full range of activities they engaged in at home, although a few were highly aware of it.

The $2^{\text {nd }}$ phase consisted of 11 focus groups, and here the intent was sixfold: to find out:

1. the range of activities actually performed

2. whether the activities change over time

3. which activities are considered work and which are considered non-work

4. why activities are considered work or not

5. what they learn through their activities and

6. how they learn what they learn

The major emphasis in this phase was on understanding the conception of work, both unpaid and paid.

Groups ranged in size from 4 participants to 9, with a total of 66 participants. The ages of participants ranged from 23 to 84 years. With respect to racial/ethnic background, most groups were homogeneous:

1 group of older white women

1 group of younger white women

1 group of mixed age white women

2 groups of disabled women (1 white, 1 racially mixed)

2 groups of black women

1 group of Aboriginal women

1 group of recent Chinese immigrant women

With respect to family status, within the groups

- $52 \%$ had children at home, $48 \%$ no children

- $14 \%$ were never married

- $62 \%$ were currently partnered

- $21 \%$ were separated or divorced

- $3 \%$ were widowed

With respect to income

- $50 \%$ had a personal and $11 \%$ a household income below $\$ 20,000$ 
- $\quad 5 \%$ had a personal and $11 \%$ a household income over $\$ 100,000$

With respect to paid work:

- $31 \%$ were working full-time for pay

- $22 \%$ were working part-time for pay

- $12 \%$ were full-time students

- $35 \%$ were not working for pay

In other words, it was a highly diverse set of groups, with one exception: in terms of education, our participants were disproportionally well educated - only $8 \%$ had high school or less, and $30 \%$ had a graduate degree.

In the groups we asked respondents, whether they did any or all of the following activities:

- provide emotional support to someone (comfort, console, counsel, give advice, listen) -parallel to Hochschild's studies of emotion work (Hochschild 1989; Hochschild 1997)

- organise, plan, manage or arrange matters (e.g. family events or schedules, arrange repair people, tutors, play dates for children) - parallel to DeVault's work on food provision (DeVault 1991)

- deal with crises

- maintain contact with family members or friends through telephoning, writing letters or visiting - parallel to Stack's notion of "kin keeping” (Stack 1997)

- take care of yourself

- resolve conflicts

Without exception, people in each of the groups would agree that this was certainly what they did. One participant exclaimed spontaneously "This is my life!" while the others in the group nodded and agreed verbally.

Phase 3 consisted of a follow-up interview with 70 people who had responded to the WALL survey and who had gone through a major life change within the last 5 years:

5 women and 5 men who had lost a job

5 " " 5 " 5 " who had taken a new job

5 " " 5 " " " who had lost a partner

5 " " " 5 " " 5 who had acquired a child

15 " " 5 " " 5 who were disabled

15 " " 5 " who had immigrated to Canada from China

This aspect of the study focuses on the learning that is attached to the major life change. The data collection of this phase is completed, but some of the transcriptions are still ongoing. 
Phase 4 is currently under way and consists of interviews with 10 house cleaners and 10 nannies who do the same work for pay and without pay. This phase focuses on the difference in the work when it is done for pay and without pay.

\section{Current Definitions of Household Work}

Looking at current definitions of housework, we find two predominant approaches:

1. Housework (or domestic labour) is treated as a self-evident category and not defined at all.

2. In lieu of a definition we find an operationalization of housework through a list of tasks that are identified (Perry-Jenkins and Crouter 1990; Horrell 1994; John and Shelton 1997; Sanchez and Thomson 1997; Kamo and Cohen 1998; Baxter 2000; Kamo 2000; Rivières-Pigeon, Descarries et al. 2001; des Rivières-Pigeon, SaurelCubizolles et al. 2002; Bittman, England et al. 2003). This comes in a number of variations. Some authors provide lists of specific tasks (cleaning, meal preparation, shopping, etc.)

3. .One variation lists broad areas of activity (e.g. housekeeping and childcare tasks). Another variation employs the third person criterion - only such activities are included that can be delegated to a third person, such as cleaning, cooking etc., but activities that benefit the doer of them (watching a film, taking a bath, etc.) are excluded (Chandler 1994; Ironmonger 1996). In all instances, however, it boils down to a list of activities selected by the author, rather than the participants. By contrast, the definition we are proposing is generated through the responses in the focus groups.

Beyond the operationalization of the concept that we found problematic, an analysis of the sociological literature demonstrated a few other characteristics we wanted to test empirically.

\section{Treating housework as unchanging vs. changing}

First, the very lists imply that the activities are unchanging. One always needs to clean at least a bit - provide food, clean clothes, etc. However, we found that housework and care work varies drastically by one's life cycle stage. The nature of the tasks change e.g. children grow older, parents grow frail, friends fall ill.

If we simply ask what people do, these changes may not be apparent. When we asked in the focus groups how their life, and therefore their housework and care work had changed over the last five years, we found two types of changes: dramatic changes and gradual changes that take place over time. An example of a dramtic change is provided by Rosie, a young black mother who reflected that five years ago she was living with her grandmother, now she was in a new union and helping to raise a step-child. The step- 
child has asthma. This has major implications for her housework and care work:

So there's a lot of things ... the house has to be clean, no dust, you know, regular maintenance of you know his room, especially, and the carpet in his room, making sure that he's always at the doctor, and you know, making sure that he's well taken care of. ... he's my boy as much as he is my boyfriend's boy, and like I sacrifice for him. You know, there's a time when I want these shoes, and it's like ok I can't buy it, because he needs something. So it's just constantly compromising and putting others before yourself.

The presence of the child has an effect not only on the cleaning requirements, but also on her financial management and her time management (he needs frequently to be taken to the doctor).

An example of a gradual change is provided by Alberta, a retired white woman in her 80 s. She muses:

When I was working, I used to come home every Friday night, and I cleaned my house from top to bottom, did all my laundry, and everything. Now my house is lucky if it gets hoovered once a month. (laughter). I just can't - I don't understand how I did that, worked all day till 5, came home and did all this, you know? And now, I look at the dust on the coffee table and I pat it and I say, maybe tomorrow. (laughter) ... I was always known to my brothers as the cleaning bug, "she's forever cleaning." And they were laughing when I told them. ... I had to do it a wee bit more regularly when I had my dog. Because of the hair and everything. But now I can't be bothered. I can get up in the morning, and come through, and sit, and have my breakfast, and don't bother. I mean, I'm involved in so much community work, my council work and everything, that I [don't] have time for that. But as far as cleaning the house, and like - one of the ladies said she does the dishes once a day, well I do them maybe once every two days. They get a rinse and that's it. But it's true. It seems to be that we adopt a different attitude when we seem to reach the age, I think - I did it at 75.

When we asked "What changed?" she simply answered "I changed".

Conceptualizing housework as performed by wives and husbands (women and men) only within their own household vs. conceptualizing it as also performed by others and across households.

Second, sociologists seem fascinated by figuring out how much housework is performed by wives vs. husbands. The answer is that wives always perform more housework, although the size of the gap varies. While this is, indeed, an important issue, the consequence of this preoccupation is an image that housework is basically performed by wives and husbands, sometimes women and men, within their own homes. Very rarely 
are children included as not only creating work, but also doing some work. What is missing in this picture is the paid and unpaid work by adults other than husband or wife that is performed within one's household, and the fact that many people perform housework outside of their own homes.

Our questionnaires showed that 59\% percent of the women said that they performed some unpaid housework for someone outside of their own household, $49 \%$ said they received such unpaid out-of-household help, and $48 \%$ received some form of paid help with their household work. Putting these various activities together, $76 \%$ either received and/or provided unpaid help with housework, and if we add paid help into the equation, a total of $86 \%$ of the women indicated that there was some exchange of housework across households on either a paid or unpaid basis. We cannot generalize these findings, since we used an opportunity sample, but it does demonstrate that a) housework is performed across and not just within one's own household, and b) housework is performed by people other than just wives and husbands - it includes adult children, parents of adult children, friends, neighbours, and others.

The lists of activities typically focus on the repetitive, mundane tasks - cleaning, cooking, taking our the garbage, etc. Only rarely do they include the mental aspects, even less often the emotional aspects, and never the spiritual aspects - which we found in our focus groups to be important for our respondents.

Focussing on the lower-level physical work rather than higher-level work including mental and emotion work.

Third, the lists typically include housekeeping activities such as cleaning, cooking, shopping, that are considered mundane, repetitive, and requiring low skill. This ignores that much housework is also mental work as well as emotional work. Some of it requires sometimes very complicated planning, often the more complicated the more people live within a household. Other aspects involve careful - and sometimes exhausting - emotion work. For instance, one of our Aboriginal women described how she had to deal with her brother until it was recognized that he was a schizophrenic.

Integrating care work incompletely through including childcare but excluding all other care work vs. integrating all care work into housework

Finally, childcare is often included under housework. This means, that the current understanding of housework includes a portion of care work, but excludes other care work. If someone is looking after an aged parent, or a disabled adult child, sibling or spouse, this is typically excluded. This makes little sense. We therefore include all care work under the overriding concept of housework.

\section{A New Definition of Household Work}

On the basis of our data we have defined housework as follows: 


\section{Housework consists of the sum of mental, emotional, physical and spiritual activities that are performed for one's own or someone else's household to maintain the daily life of oneself or others for whom one has responsibility.}

This definition is quite different from current definitions. Briefly, it foregrounds the mental and emotional tasks over the physical tasks. It adds a spiritual dimension which is has so far not received attention in scholarly housework research. It integrates all caring functions with housekeeping functions. This solves the dilemma that is currently created through the artificial overall separation of these two functions with the partial integration of some aspects of care work - namely childcare - with the concomitant exclusion of care for adult children or other adults. It allows for the possibility that housework may be exchanged across households and that it may change with the people for whom one has responsibility - in other words, that it changes with the life cycle. It thus allows the creation of a dynamic rather than a static picture of housework.

\section{Unpaid Housework and Lifelong Learning}

The next comments are still tentative, since we have just started the analysis of the learning part. I $\mathrm{m}$ here drawing on only 10 of the 70 interviews we conducted in our follow-up with the WALL respondents. These are the 5 women and men who were selected because they lived in Toronto, had volunteered for a follow-up interview during the WALL survey and had lost a partner through divorce, separation or death within the last five years. The hypothesis behind this was that people who had lost a partner would have to learn to live differently, which would require different skills in their housework. However, we asked respondents to identify the major events that had happened to them in the last 5 years and then select the one that was most significant for their housework. If they identified another event, the interview used the event they had chosen as the focus for learning.

\section{Dimensions of Learning}

Following our definition of housework, I am examining whether people who had gone through a major life change (phase 3 ) learned something within each of the four dimensions of housework we had identified earlier: mental, physical, emotional and spiritual (in phase 2).

The questions were not phrased around these four dimensions, but instead around some very concrete skills (e.g. did you learn to cook differently because of the major event?), some more abstract questions (e.g. did you learn to solve conflicts differently because of the event?) and some very broad questions (did you think about yourself differently? and did you learn something about the meaning of your life?)

Fitting the answers within three of the four categories was simple, the only case in which there were some difficulties was in the dimension of physical learning - for the simple 
reason that no task is simply physical, there is always a mental element attached to it. I therefore reinterpreted this dimension as referring to relatively simple, basic skills that have a clear physical aspect.

\section{Learning about physical, basic tasks}

We did find that for some people there was considerable learning about very simple basic tasks. For instance, Jeffrey, a 58-year old postal worker, whose wife divorced him five years ago, obviously had not done much of the regular housework while he was married. After the divorce, he had to learn how to cook and clean. As an example, with respect to cooking, he learned that

You can't rush things. You can't turn the heat up high thinking it's going to get done faster.

He also learned that you cannot use ordinary soap in a dishwasher and that you cannot cook eggs in the microwave.

Sondra, a retired Superintendent of Community Services, had to learn a number of basic skills after the death of her husband - how to put the extension leaf into the table, and how to move furniture by herself. "I remember buying these things from Canadian Tire that you put under pieces of furniture that you can move, which I would never have needed previously because there's two people to move things ..."

Munaza, a doctor from Pakistan, whose husband had tricked her into emigrating to Canada, then stayed in Pakistan himself with his new love, had never cooked before, nor cleaned, nor shopped, nor looked after her own children. The cooking was done by her mother, mother-in-law and servants, her mother would buy produce from carts that came to the house and sold their wares at the door, and other regular housekeeping functions such as cleaning, doing the laundry, picking up things, etc. were all performed by servants.

She arrived in Canada in the winter with two small children, very little money, no friends, and no job. She had to learn how to clean, to shop for unfamiliar items, to cook, to tidy up, to do the laundry, and how to deal with her own children. She has not yet made close friends, but she learned from neighbours, TV - especially the cooking channel - reading, the internet, trial and error, and from her children.

\section{Learning about mental tasks}

A number of people learned about tasks that can be clearly categorized as mental skills, such as time management, organizing one's house and life, budgeting their finances, etc. Munaza said that due to her move to Canada and having to learn to run her own household: "I am a more skilled organizer, as far as household is concern." Overall, 
however, this was not a subject that was mentioned frequently. Indeed, more people said that they had unlearned organizational skills than learned. For instance, Sondra, noted that after her retirement "if anything, I've become more disorganized than I used to be." Compared to a paid job that requires a certain type of organization, the structure of housework is to a greater degree created by the self, which is a more difficult thing to achieve.

\section{Learning about emotional work}

The big surprise was that each of the respondents stated that they had learned how to deal with emotions better. They had all sustained a loss, although the severity of the loss was very different. At the one end, Jimmy, a young man who had split up with his girlfriend had since married another woman, at the other end, Teddy, in his early 70s, had lost his wife of 53 years and was still grieving.

Nevertheless, going through a loss made everybody in this group except for one woman more empathetic. They learned what behaviour is helpful and what is not helpful: listening is helpful, immediately mentioning their own experiences is not helpful, being open to someone else's concerns and making oneself available when someone else has a need to talk is helpful, initiating a contact in such a situation also helps. They all professed to be more proficient in this area than before the event.

Munzana, a doctor from Pakistan who treated a lot of refugees describes how what she has learned since she came to Canada will be useful for her work as a doctor. A highly self-reflective woman, she talks about how dealing with her own children has taught her patience, and how she would apply this - and the experience of her own pain - in her work. In Pakistan, she understood the pain and frustration of her patients intellectually, but she never related it to herself, because they were clients, she was Pakistani, and on the other side of the table. "But now I know what they would have gone through, because now I consider myself in the same position, when I am applying for the job or anything." Now she has herself experienced "the pain they were going through", and she feels that this will make her a much better doctor - once she manages to get a job in Canada in that capacity.

The one exception to learning emotion work, Marie, a 65-year old woman who was widowed twice said "I don't have any family. They are all gone. There isn't a soul that's alive." She made this statement in spite of the fact that she lives together with her 44-year old son. She is clearly isolated, and not a person who would easily trust anyone. "I'm not saying that I don't trust the odd friend, but basically speaking I don't trust anybody." Nevertheless, she does claim that she is good at listening to other people, but says that she has not "learned anything! I just automatically know what to do." However, considering her degree of social isolation, her skills at emotion work do not seem very convincing.

Spiritual learning 
We define as 'spiritual' anything that gives meaning to one's life. iv We asked people whether because of the event (either the loss of their partner or whatever they had defined as most important) they thought about themselves differently and whether it had changed the meaning of their lives. We introduced this question because this was a prominent and completely unexpected part of our findings in phase 2. Especially the disabled women, the black and Aboriginal women talked about spiritual learning. We were not sure what to expect, but after some initial surprise all respondents gave thoughtful answers to both questions, and all indicated learning in this area.

Sondra reflects that the meaning of her life is different now that she no longer has her challenging job. "I guess what gives life meaning ... now is to reflect back on the contributions I made, and how in many cases people have gone and built on those, have taken work I started and advanced it, so that's very satisfying."

Teddy, whose wife died unexpectedly, has learned to do "things when you are able to do them, and don't keep putting them off. There were a lot of things that we were going to do that we ... kept putting off, and, darn it, we shouldn't have done it."

Jay, a Japanese handyman, who had broken up with his girlfriend, but had since acquired a new girlfriend, was reflecting on what he owed his parents. His older brother was thinking of taking his wife's name, which put the onus on Jay to provide a child that would carry on the family name - the one thing that he felt he owed his parents. His parents brought him into the world - he felt he needed to repay them by bringing forth the next generation, and felt torn between this

obligation and the fact that his girlfriend could not have children.

\section{The mode of learning: social vs. individual}

We tend to think of housework as being carried out within one's own home and therefore as somewhat isolated. However, when we checked how people learn, we did find that they learned by doing, reading, from TV/radio, tapes and videos, the internet etc., all of which are activities which may be carried out alone, but we found an even stronger social component. Everybody said that they learned from someone more knowledgeable than themselves, as well as from professionals.

Table 1

Modes of Learning by number of people who mentioned it:

\begin{tabular}{|l|l|}
\hline Mode of learning & \# of people who mentioned it \\
\hline Learn from someone more knowledgeable & 10 \\
\hline Learn from professionals & 10 \\
\hline Learn by doing & 9 \\
\hline
\end{tabular}




\begin{tabular}{|l|l|}
\hline TV/radio & 7 \\
\hline Trial and error & 7 \\
\hline Discussion with friends/others & 6 \\
\hline Reading & 5 \\
\hline Experience & 5 \\
\hline Watching someone else do it & 5 \\
\hline Just know how to do it & 3 \\
\hline Internet & 2 \\
\hline Classes & 1 \\
\hline Therapy & 1 \\
\hline
\end{tabular}

While much of the learning is experiential (learning by doing) and an important part can be carried out by a person alone, it is clear that there is a very strong social component.

\section{The Failure to Learn}

Most people learned significantly through their housework. However, we also found instances in which people did not learn. We believe that it is just as important to study when people learn as when they fail to learn.

I will briefly consider the case of Teddy, a man in his early 70's who had recently (less than a year before the interview) lost his wife of 53 years. This man had clearly led a marriage with a traditional division of labour, in which the wife did all the housework. Her death deprived him not only of her company, but also of the comforts that go along with having someone else perform all the housework on a daily basis.

Due to the fact that his wife did the housework, Teddy found himself at a loss with many things when she suddenly died. While he learned some of the basic skills such as using the microwave oven, cooking remained a big problem for him. He stated emphatically that it is "one of those things I can't do", only to observe that he does no want to do it, "maybe that's it".

His daughter comes once a week on Sundays and cooks a meal for him. She also prepares a shopping list for him. His neighbour prepares an occasional meal, and recently he had taken Meals on Wheels for the rest of the time. Although he complained about the quality of the food, he did not learn to cook, nor did he want to learn. He said quite clearly that he was not a cook. "I never was, I never will, I hate doing that sort of stuff." As a consequence, the quality of his life has been drastically reduced.

He also needs a cataract operation, but is concerned how to put in the drops. He is not sure he can do that by himself. "So, I've put that off for this year, and hopefully it won't get so bad that they can't be done next year sometime." 
He has learned other things: for instance, to be careful to use his puffer four times a day, to provide emotional support to a friend of his wife in need of support, to be more sympathetic when someone has suffered a loss, and to clean windows.

He has not learned to organize a situation so that someone would be able to help him with his eye drops if he is not able to do it himself, to cook properly or to do his laundry. Indeed, he has not tried to learn these skills.

Teddy is not the only one who has not learned certain skills. Most of the respondents mentioned things that they had not yet learned something when we asked about this. For example, Kathryn feels that she needs to learn to organize her time better, Jimmy feels that he has more to learn with regard to buying household cleaners, Sondra would like to become more efficient in her housework, John is planning to learn to handle his sleep, his debt and his stress better, and so on. The difference between Teddy and the others is that Teddy is unwilling learn, whereas the others intend the learn the skills they mention. It seems that willingness to learn as well as failure to learn should be routine issues looked for in all instances when studying life long learning.

\section{Conclusion}

As we have seen, housework leads to learning that is mental, physical, emotional, and spiritual. Given that I have here considered only one subset of the interviews we conducted in phase 3 - those who experienced the loss of a partner within the past 5 years - it is likely that the emphases in terms of learning will be different in the other subsets.

But people not only learn - some also unlearn some skills, and some do not learn certain skills at all. This raises the question of the motivation to learn. In unpaid housework, there is no monetary gain in terms of promotion on the job, a higher salary, etc. to be gained by learning. Learning is done for its own sake - sometimes out of necessity, sometimes out of the desire to do things better. We unfortunately did not ask why people learn, we only asked what they learn, how they learn, and from whom they learn. Some, however, volunteered why they learn, and the answer was often "out of necessity". Nevertheless, some refuse to learn when outside observers would think that it would be necessary to learn something, such as in the case of Teddy who put off his cataract operation because he was afraid he would not be able to put in the eye drops?

Expanding research on lifelong learning to include unpaid housework leads us to place the emphases somewhat differently. It alerts us to the fact that learning has at least four dimensions: physical, mental, emotional and spiritual. It suggests that it may be useful not only to focus attention on why people learn, but also on why they do not learn. Applying these concerns to paid work and learning would open up some new and interesting questions. 


\section{REFERENCES}

Baxter, J. (2000). "The joys and justice of housework." Sociology 34(4): 609-631.

Bittman, M., P. England, et al. (2003). "When does gender trump money? Bargaining and time in household work." American Journal of Sociology 109(1): 186 - 214.

Chandler, W. (1994). "The value of household work in Canada, 1992." Canadian Economic Observer: 3.1-3.9.

Collins, M. (1998). Critical Returns: From Andragogy to Lifelong Education. Learning for Life. Canadian Readings in Adult Education. S. M. Scott, B. Spencer and A. M. Thomas. Toronto, Thompson Educational Publishing: 46-58.

des Rivières-Pigeon, C., M.-J. Saurel-Cubizolles, et al. (2002). "Division of domestic work and psychological distress one year after childbirth: A comparison between France, Quebec and Italy." Journal of Community and Applied Social Psychology 12: 397-409.

DeVault, M. L. (1991). Feeding the family: The social organization of caring as gendered work. Chicago, University of Chicago Press.

Eichler, M. (2005). The other half (or more) of the story: Unpaid housework and care work and lifelong learning. International Handbook of Educational Policy. N. Bascia, A. Cumming, A. Datnow, K. Leithwood and D. Livingstone, Kluwer.

Eichler, M. and P. Albanese (2004). What is Housework? Toronto, OISE/UT.

Eichler, M. and A. Matthews (2004). What is work? Canadian Sociology and Anthropology Association, Winnipeg.

Garrick, J. (1996). "Informal Learning: Some Underlying Philosophies." CJSA/RCEEA 10(1): 21-46.

Hochschild, A. R. (1989). The second shift: Working parents and the revolution at home. New York, Viking.

Hochschild, A. R. (1997). The time bind: When work becomes home and home becomes work. New York, Henry Holt.

Horrell, S. (1994). Household time allocation and women's labour force participation. The social and political economy of the household. M. Anderson, F. Bechhofer and J. Gershuny. Oxford, Oxford University Press.

Ironmonger, D. (1996). "Counting outputs, capital inputs and caring labour: Estimating Gross Household Product." Feminist Economics 2(3): 37-64.

John, D. and B. A. Shelton (1997). "The production of gender among black and white women and men: The case of household labor." Sex Roles 36(3/4).

Kamo, Y. (2000). "'He said, she said": Assessing discrepancies in husbands' and wives' reports on the division of household labor." Social Science Research 29: 459-476.

Kamo, Y. and E. L. Cohen (1998). "Division of household work between partners: A comparison of black and white couples." Journal of Comparative Family Studies.

Perry-Jenkins, M. and A. C. Crouter (1990). "Men's provider-role attitudes. Implications for household work and marital satisfaction." Journal of Family Issues 11(13656).

Rivières-Pigeon, C. d., F. Descarries, et al. (2001). "Le partage des tâches domestiques et les problèmes dépressifs: une analyse de la situation des nouvelle mères au Québec." Recherches féministes 14(2): 5-26. 
Sanchez, L. and E. Thomson (1997). "Becoming mothers and fathers: Parenthood, gender, and the division of labor." Gender and Society 11(6): 747-772.

Stack, C. (1997). All our kin. New York, Basic Books.

Williamson, B. (1998). Lifeworlds and learning. Essays in the theory, philosophy and practice of lifelong learning. Leicester, National Institute of Adult Continuing Education. 